\title{
New complication of LMA supreme and orogastric tube
}

\author{
D Amaraweera ${ }^{I^{*}}$, M Ashfaque $^{2}$ \\ Specialty Registrar ${ }^{1 *}$, Consultant Anaesthetist ${ }^{2}$, Department of Anaesthesia, QEQM Hospital, Margate, \\ $U K$.
}

*Corresponding author: doctordeepika2010@gmail.com

\begin{abstract}
A case history of a complication that occurred due to insertion of an oro gastric tube through a LMA supreme for a laparoscopic cholecystectomy is described.
\end{abstract}

Keywords: supraglottic airway; orogastric tube; laparoscopic cholycystectomy; oropharyngeal seal; oesophageal seal

\section{Introduction}

Laparoscopic cholecystectomy surgeries are done as day cases nowadays and instead of endotracheal intubation supraglottic airways are being used commonly. LMA supreme, which is a new design, causes less complications. This patient had a complication due to an orogastric tube (OGT) which was passed through the LMA.

\section{Case history}

Forty eight year old lady was admitted to the day surgery unit for a laparoscopic cholecystectomy. She was an ASA 1 patient. She had general anaesthesia with propofol and was maintained with sevoflurane. She had analgesia with fentanyl, morphine and paracetamol. She was paralysed with atracurium and LMA supreme was used to maintain the airway. 14F orogastric tube was inserted through the LMA port. Vital parameters were maintained within normal range and there were no complications till the end of the surgery. Once patient recovered from muscle relaxants, attempts were made to take the OGT out. It was impossible. She was sent to the recovery with the LMA. After a few minutes she started to desaturate and the chest movements were inadequate. We took the LMA out and maintained the airway with an oropharyngeal airway. Then her airway and breathing became normal. Finally we found that there was a knot in the OGT and it was stuck at the LMA cuff interfering with proper sealing. (Figure 1)

\section{Discussion}

Laparoscopic cholecystectomy can be done with different airway management methods which permit to keep the airway patent, prevent aspiration

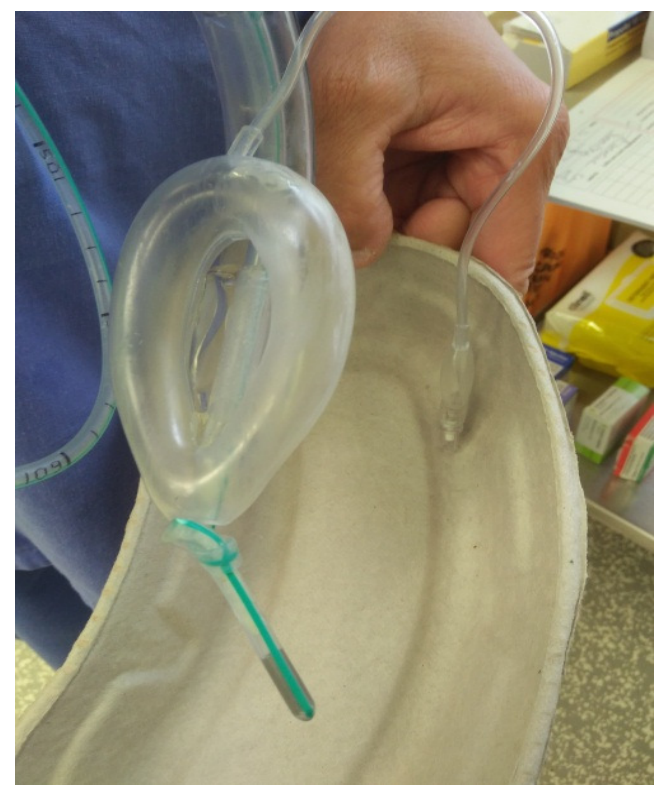

Figure 1: Knotted OGT stuck at LMA cuff

and allow positive pressure ventilation. Initially tracheal intubation was popular. LMA classic, LMA proseal and LMA supreme have been used instead of intubation for several years safely. ${ }^{1,2,3}$ LMA supreme is a single use $2^{\text {nd }}$ generation device which forms an effective seal with the oropharynx (oropharyngeal seal) and an innovative $2^{\text {nd }}$ seal with the upper oesophageal sphincter (the oesophageal seal).The importance of the $2^{\text {nd }}$ seal is significant. It

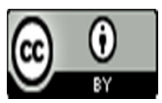


minimizes gastric insufflation and reduce the risk of aspiration. ${ }^{4}$ An orogastric tube can be used with LMA proseal and LMA supreme for gastric deflation which provides good surgical view and reduce aspiration risk further because in this type of surgeries aspiration risk is high due to trendelenburg position and capnoperitonium.

Orogastric and nasogastric tubes are commonly used in patients for different indications like draining gastric contents, gastric decompression and making passage to the gastrointestinal tract. ${ }^{5}$ In the literature a number of complications of nasogastric and orogastric tubes have been reported. Bronchial placement (leading to atelectasis, pneumonia, lung abscess) bronchial perforation, pleural cavity penetration, intravascular penetration, knotting and impaction in the nasopharynx, double backing, kinking, tube breakage, enteric perforation and intracranial entry are some of them. ${ }^{6}$

In this case the patient had a rare complication, OGT knotting in the stomach. Once we tried to pull it out the knot had tightened and got stuck at the LMA. It interfered with the oesophageal seal and oropharyngeal seal of the LMA making the patient hypoxic. Initially it was difficult for us to work out what had happened. Taking the LMA out with the OGT and maintaining the airway with an alternative way was the only solution. Patient was able to maintain the patency of the airway with an oropharyngeal airway and recovered from general anaesthesia without any further complications.

\section{References}

1. Maltby JR, Beriault MT, Watson NC, Liepert D, Fick GH. The LMA proseal is an effective alternative to tracheal intubation for laparoscopic cholecystectomy. Can J Anaesth, 2002;49(8);857-

862

http://dx.doi.org/10.1007/BF03017420

PMid:12374716

2. Maltby JR, Beriault MT, Watson NC, Liepert D, Fick GH. Gastric distension and ventilation during laparoscopic cholecystectomy; LMA classic vs tracheal intubation. Can J Anaesth, 2000;47(7): 622626
http://dx.doi.org/10.1007/BF03018993

PMid:10930200

3. Belena JM, Gracia JL, Ayala JL, et al. The laryngeal mask airway supreme for positive pressure ventilation during laparoscopic cholecystectomy. J

clinanaesthesia.2011;23(6):456-460

http://dx.doi.org/10.1016/j.jclinane.2011.01.004

PMid:21911191

4. Gilles D. LMA better by design. www.secondsealconfidence.com

5. Richard A, Liliana B, nasogastric and nasoenteric tubes, Up to Date, 2016.

6. Pillai JB, Vegas A, Brister S. Thoracic complications of nasogastric tube; review of safe practice, interactive cardiovascular thoracic surgery. Interact CardioVascThoracSurg 2005;4(5):429-433. http://dx.doi.org/10.1510/icvts.2005.109488

PMid:17670450 